\title{
Corporate political activity as part of enterprise strategy in South African agribusinesses
}

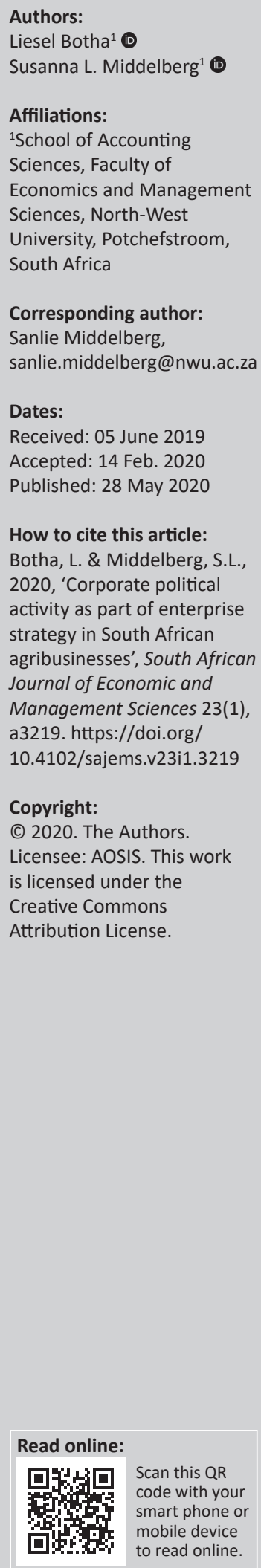

Background: The South African agricultural sector is facing regulatory uncertainty relating to land reform and distribution, restrictive labour policies and minimum wages. Corporate agribusinesses play an important role in the agricultural industry. Increasing political influence on their activities manifested in the lack of government support, and the uncertainty surrounding public policy threatens investment and growth in the sector. This calls for an intelligent integrated enterprise strategy that includes corporate political activity (CPA).

Setting: Four South African agribusinesses and two agricultural associations.

Aim: The purpose is to explore the CPA adopted by corporate agribusinesses and agricultural associations in terms of enterprise strategy during times of regulatory uncertainty.

Method: Qualitative data were collected through semi-structured interviews. A questionnaire, consisting of sections focused on regulatory uncertainty, responses to regulatory uncertainty and strategy, was completed during the interviews.

Results: The participants experience significant regulatory uncertainty. There is a clear distinction between the strategic approach to CPA followed by corporate agribusinesses and agricultural associations. The parties surveyed pursue a combination of CPA strategies. A desire for greater cooperation and shared prosperity with government is evident, supported by a strong sense of conducting business ethically, traced across the results.

Conclusion: This article addresses the role that CPA plays in an integrated enterprise strategy - especially in times of regulatory uncertainty - such as the agricultural industry in South Africa is experiencing. It not only reports on the CPA approach of both corporate agribusiness and agricultural associations, but also describes the strategies agribusinesses follow during times of uncertainty.

Keywords: Corporate political activity; Enterprise strategy; Agribusiness; Agricultural associations; Policy uncertainty; South Africa

\section{Introduction}

The South African agricultural landscape is facing regulatory uncertainty with the government having influence over restrictive labour policies, minimum wages, as well as land reform and distribution (Chamberlain \& Anseeuw 2018; Hall 2004; Middelberg 2013; Ortmann 2005). With increased political influence, the ability of businesses to affect government policy forms part of an integrated enterprise strategy (Kingsley, Berg \& Bonardi 2012:53; Liedong et al. 2015:408). Schendel and Hofer (1979:12) described enterprise strategy as the role of the firm in its broader social, legal and political (i.e. non-market) environment. Corporate agribusinesses play an important role to influence public opinion in such non-market environments (Griffin \& Dunn 2004). Especially as the leadership of corporate agribusiness and large-scale commercial farming has seen consolidation over the last two decades within agricultural value chains (Hall \& Cousins 2018:12). Increasing political influence on South African agribusinesses, manifested in the apparent lack of government providing support services (Khapayi \& Celliers 2016:39) and policy uncertainty (Hendriks 2013:3), threatens development in the sector (Smith 2016). This calls for an intelligent integrated enterprise strategy that includes corporate political activity (CPA) - concisely defined as activities aimed at influencing governmental regulations and policies in favour of corporate agribusiness (Hillman, Keim \& Schuler 2004; Lawton, McGuire \& Rajwani 2013; Mbalyoherea \& Lawton 2018:369).

The South African agricultural sector is considered one of the most employment-intensive sectors of the country's economy with primary agriculture employing 4.5 additional workers for every ZAR1 million in capital invested (in comparison with 2.94 for the economy as a whole) (Boshoff, Sihlobo \& Ntombela 2018:4). Taking into account its indirect role in terms of the backwards and 
forwards linkages with other sectors, it contributes almost 7\% to gross domestic product (GDP) (Boshoff et al. 2018:4; South African Government 2016). The insight that collaboration with a broad range of stakeholders - including government in the political arena - influences corporate value creation and ultimately business sustainability has moved the focus away from shareholder value as the main management concern (Crilly 2013). This echoes Baron's (1995) work that non-market strategies become more important where opportunities are controlled by government. Uncertainty regarding, among others, land policy (Chamberlain \& Anseeuw 2018; Hall 2004), development financing (Ncube 2018:89) and water policy (Fanadzo \& Ncube 2018:436; Greenberg 2010) is making it increasingly less likely that investors would consider the agricultural sector as an investment option (Vorster et al. 2016). This is also considered one of the reasons why the average age of farmers in South Africa is increasing. The younger generation is not willing to farm due to the policy uncertainty and political statements by government (Willemse, as cited by Booysen 2016). Furthermore, government does not yet have a 'scalable solution for making agriculture more remunerative' for the youth (Swarts \& Aliber 2013:26).

The question arises: do South African agribusinesses address this regulatory uncertainty through CPA as part of enterprise strategy? And if so, which CPA strategies do they follow? The term agribusiness includes, for the purposes of this article, all businesses involved in the management of multiple value chains that deliver goods and services by sustainably coordinating food, fibre and renewable resources to serve national and international consumers, as well as those that provide finance and other market advisory services to primary producers (Middelberg 2011; Shultz \& Edwards 2005).

The extant literature is primarily focused on CPA's relationship with firm performance - that is, whether CPA leads to improved firm performance (Boubakri, Cosset \& Saffar 2012; Curran \& Eckhardt 2018; Hadani \& Schuler 2013; Hillman et al. 2004; Liedong 2013; Mellahi et al. 2016; Wu et al. 2012). Limited research (Moodley 2013) has been done on the relationship between CPA and an integrated enterprise strategy during times of regulatory uncertainty. Lawton et al. (2013:97) posit that the CPA function is a 'largely unexplained and indeterminate variable within companies' strategic decisionmaking processes'. This relationship is not considered a developed and sophisticated research area yet and has hardly been studied in developing countries (Liedong 2013; Mellahi et al. 2016). Liedong (2013) goes as far as describing Africa as a 'virgin region' with regard to CPA research. It is our intention to take the first step in this limited investigated area to report on CPA research in the South African agricultural sector - a sector identified as regulatorily uncertain (Hendriks 2013).

The aim of this article is to explore the CPA adopted by selected South African agribusinesses in terms of an integrated enterprise strategy, especially during times of uncertainty.
There is a need to understand the role that CPA plays in an enterprise strategy and how it best can support the business in engaging with government, especially in addressing the regulatory uncertainty and in turn drawing investors to the corporate agribusinesses and sector as a whole. As mentioned previously, agribusinesses and commercial farming are closely aligned. The latter plays a fundamental role in providing food security in a country plagued by unemployment and exceptional high child undernourishment (Hendriks 2013). It is in the interest of both policymakers and agribusinesses to identify and implement the most effective strategies in the current set of uncertain circumstances, and this article aims to contribute accordingly. Additionally, this article is unique as it reports on CPA from the viewpoint of corporate agribusinesses and agricultural associations - both key players in the South African agricultural sector.

The rest of the article will present a literature review on the topic of CPA, followed by a discussion of the research design and data collection. The third section will communicate the results, while the fourth section will discuss the results and make recommendations. The final section will conclude with closing remarks.

\section{Literature review Conceptualisation of corporate political activity}

It has long been recognised that political considerations must form part of long-range corporate planning (Keim 1981). Around the same time, the concept of CPA was defined by Baysinger (1984) as being corporate engagement in external political activity in an attempt to shape policy in ways favourable to the firm. A number of subsequent definitions of CPA are available, but the gist of them is founded on Baysinger's version and culminates in corporate attempts to influence government policy to fit business interests (Hillman \& Hitt 1999; Hillman et al. 2004; Tian \& Deng 2007). Corporate political activity, simply put, navigates itself to the 'sweet spot' found in the overlap between what the firm wants, what the government desires, and what the business can do to achieve what they both want (refer to Figure 1).

In their seminal work on corporate political strategy (CPS) formulation, Hillman and Hitt (1999) elaborated on the theoretical constructs of CPA with specific reference to: (1) response strategies, (2) strategy types, (3) types of CPA proactive or reactive - and (4) approach to CPA. These constructs form the foundation of the empirical work of this study (refer to Table 1).

\section{Previous research on corporate political activity}

A recent study on engaging multinational enterprises' stakeholders through CPA was conducted by Mbalyoherea and Lawton (2018) in Uganda. They investigated how such enterprises engage stakeholders through CPA during the reform of the country's electricity generation sector. Data were collected through semi-structured interviews, archival materials and fieldwork notes. These authors argue that the 
most important stakeholder remains the host government during the early stages of reform. However, as the reform process advances, strategic adaptations are required. The implications of the research are that although the multinational enterprises deployed CPA-driven non-market strategies, they are dependent on the government in Uganda creating an environment and opportunity in which to engage. The study focused on the electricity industry with a recommendation that similar studies should be conducted in other industries. Our study is focused on the agricultural industry in South Africa - an industry that will greatly benefit from research on CPA as it is facing political and policy uncertainty (Hendriks 2013).

Moodley (2013) explored the possible differences in CPA of multinational and local companies in the South African health sector - another sector faced with regulatory uncertainty. The findings highlighted that although there was general alignment in CPA between the two groups of companies, the multinationals were more proactive than the local companies in approaching government. Furthermore,

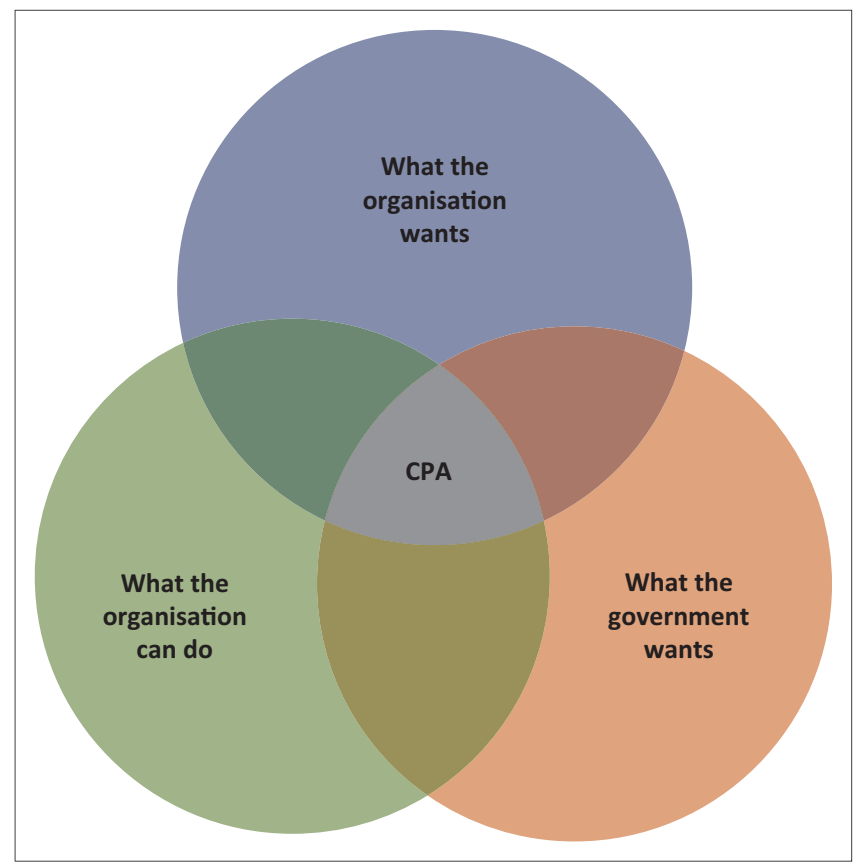

Source: Adapted from Caspari, C. \& Caspari, M., 2016, 'Strategic planning moving ideas to practice', Camping Magazine 89(2), 56.

CPA, corporate political activity.

FIGURE 1: Corporate political activity. local companies adopted an avoidance strategy during times of uncertainty, while companies with a 'higher turnover are more proactive and relational in their approach to CPA' (Moodley 2013:77).

As mentioned earlier, the literature has generally focused on the relationship between firm performance and CPA (Curran \& Eckhardt 2018; Hillman et al. 2004; Mellahi et al. 2016). It reveals that this relationship is mixed (Liedong 2013; Mellahi et al. 2016; Sun, Mellahi \& Wright 2012). Politically connected firms in 23 different countries demonstrated an increase in business performance, financial leverage and the use of longterm debt and liquidity ratios after establishment of the connection (Boubakri et al. 2012). Sun et al. (2012) averred that corporate political ties generate substantial strategic value for firms. Studies in China also found positive yields on political connectedness ( $\mathrm{Lu}$ 2011; Wu et al. 2012).

In contrast, however, there is evidence of an increasing negative correlation between $\mathrm{CPA}$ and organisational performance. In a review of 56 studies of CPA and firm performance conducted between 1988 and 2013, Liedong (2013) found that $12.5 \%$ of these investigations provided evidence of a negative relationship between them. Seventy per cent of the studies that produced negative results were conducted between 2011 and 2013. Similarly, in a comparable project undertaken by Mellahi et al. (2016), more than half of the empirical studies (10 out of 18) reviewed, conducted between 2010 and 2014, did not find a positive relationship between CPA and performance. Studies in the United States and Malaysia also indicated corresponding negative relationships (Aggarwal, Meschke \& Wang 2012; Bliss \& Gul 2012; Hadani \& Schuler 2013).

These negative relationships can be explained by the 'darker side' of CPA. Society might perceive CPA to be negative in those instances where business-government relations are believed to be unethical (Liedong et al. 2015). This particularly applies to emerging markets where high levels of corruption between business and the state are thought to prevail (Doh, Lawton \& Rajwani 2012). The difference between legitimate participation in democratic decision-making and the opportunistic pursuit of self-interest has become confusing in recent years. This unethical CPA could tarnish the reputation of a firm (Hond et al. 2014).

TABLE 1: Empirical framework to establish enterprise strategy during times of regulatory uncertainty.

\begin{tabular}{|c|c|c|}
\hline Design step & Questionnaire section & Content \\
\hline $\begin{array}{l}\text { Assess regulatory uncertainty within } \\
\text { sector and business }\end{array}$ & Section 2 & $\begin{array}{l}\text { Understand the regulatory environment within agricultural sector: general direction, } \\
\text { operationalisation, implementation process, interaction between new and existing legislation. }\end{array}$ \\
\hline $\begin{array}{l}\text { Identify current responses to regulatory } \\
\text { uncertainty }\end{array}$ & Section 3 & $\begin{array}{l}\text { Determine how businesses respond to regulatory uncertainty. Thirteen responses were identified by } \\
\text { Engau and Hoffman ( } 2011 \mathrm{a}) \text {. These responses are then further grouped into four strategies - avoid, } \\
\text { reduce, adapt or disregard. }\end{array}$ \\
\hline Review current CPA strategies & Section 4 & $\begin{array}{l}\text { Based on the participants' response strategies, it can be established whether they are: (1) engaged } \\
\text { in either proactive or reactive CPA (i.e. do they engage proactively with government or reactively), } \\
\text { (2) their approach to CPA - relational or transactional, (3) participation level in CPA and (4) strategy } \\
\text { types. }\end{array}$ \\
\hline Devise an appropriate strategy & - & Recommendations are made based on the results. \\
\hline
\end{tabular}

Source: Adapted from Engau, C. \& Hoffmann, V.H., 2011a, 'Corporate response strategies to regulatory uncertainty: Evidence from uncertainty about post-Kyoto regulation', Policy Sciences 44(1), 53-80. https://doi.org/10.1007/s11077-010-9116-0; and Moodley, T., 2013, 'Corporate political activity : A comparison of local and foreign company strategies', MBA dissertation, GIBS, University of Pretoria

CPA, corporate political activity. 


\section{An overview of the institutional context of South Africa}

Engau and Hoffmann (2011a) identified two main factors that warrant specific consideration in deciding on a strategy: (1) the perceived level of regulatory uncertainty and (2) the firm's exposure to future regulation. They found that higher levels of uncertainty lead to a broader range of strategies, and the greater a business's exposure to regulatory uncertainty, the higher the participation levels in CPA. Kingsley et al. (2012) concurred that a proper integrated strategy is dependent on a thorough analysis of an entity's exposure to regulatory uncertainty. Failure to align non-market strategies with regulatory uncertainty will have a negative impact on the commercial success of the firm. A non-market strategy is a pre-arranged - and intentional - action plan taken in the non-market environment to increase overall organisational performance (Baron 1995:47). Where political markets are ideologically motivated and competition between policymakers is low, regulatory uncertainty is higher (Kingsley et al. 2012).

The two factors that should influence the decision on a strategy, as identified by Engau and Hoffmann (2011b), warrant consideration in the South African context. The current South African political arena is dominated by the African National Congress, whose ideal in terms of land is that it 'shall be shared amongst those who work it' (African National Congress 2016:1). This was reiterated at the party's 54th annual conference held in Midrand, South Africa, in December 2017. The party resolved that the expropriation of land without compensation should be among the mechanisms available to government to give effect to land reform and distribution while maintaining economic stability, food security and agricultural production as a priority (Boshoff et al. 2018; Ramaphosa 2017). The dominating presence of the African National Congress has been evidenced by the most recent national election results of 2019. The party won the election with a 57.5\% vote and the Economic Freedom Fighters, another political party, obtained a $10.79 \%$ vote nationally (Electoral Commission 2019). The Economic Freedom Fighters shares a similar view in respect of land to that of the ANC as its first pillar of economic emancipation is the 'expropriation of South Africa's land without compensation for equal redistribution in use' (Economic Freedom Fighters 2019:1).

Further describing the institutional environment is the fact that there is no legislation governing private donations to political parties in South Africa (February 2017). February (2017) argued that this creates ample opportunity to buy influence and to engage in corruption, and so casts doubt on the integrity of policy decisions. South Africa obtained a bleak corruption perception ranking of number 73 out of 180 countries in 2018, with a corruption perception index of 43 . The corruption perception index scores countries in terms of perceived corruption, where a score of 100 represents a 'clean' country and a score of zero represents a highly corrupt state (Transparency International 2018).

\section{Research design and data collection}

In this exploratory, qualitative study, data were collected through semi-structured interviews. The participants were selected using purposive sampling, a non-probability sampling technique. Neuman (2014) points out that in qualitative studies, the aim is not to select a sample that is a mathematically accurate representation of the entire population, but rather to select participants based on their specific qualities and characteristics, something that the researchers specifically had in mind (Etikan, Musa \& Alkassim 2016). Purposive sampling was employed using the following criteria: all the respondents had to be employed in the agricultural industry, either by a corporate agribusiness or an agricultural association. Furthermore, they had to be familiar with their enterprise's strategy. Six individuals were selected to interview, representing middle management or above: two chief executive officers, one group managing director, one group director of business strategy, one group company secretary, and one legal and policy advisor.

These six interviewees represented two groups: (1) four corporate agribusinesses with the aim of generating profit and (2) two agricultural associations - representing the first group as a collective to serve the overarching business interest of its members - with a non-profit goal. The combined turnover of the four corporate agribusinesses was ZAR24.6 billion (approximately US $\$ 1.76$ bn using an exchange rate of $\mathrm{R} 1=\$ 13.98)$ for the 2016 financial year. These two groups were chosen to obtain a balanced view - from the firm level and from the associations representing these companies.

Semi-structured interviews are typically scheduled in advance and have an overall topic, targeted issues and specific questions. These types of interviews are not as rigid as structured interviews, but have more focus than the unstructured kind (Tharenou, Saks \& Moore 2007). Semistructured, in-depth interviews are the most popular interviewing method for qualitative research (DiCicco-Bloom \& Crabtree 2006). In this study, these requirements were met by arranging the interviews well in advance, with five taking place at the premises of the individual parties on a face-to-face basis, and one conducted telephonically, within a time span of one month. The interviewer (L.B.) travelled a combined distance of nearly $2700 \mathrm{~km}$ to conduct the interviews, which were based on an adapted questionnaire originally developed by Moodley (2013) in his study on CPA of local and foreign firms in the South African health sector. The questionnaire was completed and recorded by the first author (L.B.) during the interviews and afterwards transcribed. Most of the questions included responses based on a Likert scale with an opportunity for the respondents to motivate their answers. The bulk of the qualitative data was obtained by analysing the narratives provided by the participants.

The research method followed in the study was similar to that adopted by Godinez and Garita (2016), whose research was exploratory, had a small number of respondents, and where data were gathered through in-depth interviews. 
The adapted questionnaire is based on a framework developed by Engau and Hoffman (2011a) used to design an enterprise strategy to cope during times of regulatory uncertainty. Engau and Hoffman (2011a) identify the political activities firms undertake, while Hillman and Hitt (1999) identified the strategies firms follow during times of regulatory uncertainty. In Table 1, the main elements of the framework are presented, then linked to the questionnaire utilised in this empirical study and the content of the questions. The questionnaire was adapted to the South African agricultural context.

The questionnaire consisted of four sections that addressed the following topics: (1) general information, (2) regulatory uncertainty, (3) responses to regulatory uncertainty and (4) strategy. The first general information section required details about the interviewee's position in the company and the firm size, which would enhance the perceived context of the business involved. As evident in Table 1, Section 2 of the questionnaire on regulatory uncertainty was aimed at identifying the level of the participant's understanding of the regulatory environment, while Section 3 served to identify the activities and strategies followed in response to regulatory uncertainty. The last section - Section 4 - on strategy, had the purpose of revealing the types of CPA, as identified by Hillman et al. (2004:838), that the businesses involved pursue. Table 1 highlights the last step as devising an appropriate strategy. Recommendations were made by the authors to the current strategy followed by agribusinesses and agricultural associations in terms of CPA (refer to Section 5).

\section{Ethical consideration}

Ethical consideration was obtained from the North-West University, with ethical clearance number EMSREK16/ 08/26-01-02.

\section{Results}

The results are discussed in accordance with each of the sections of the questionnaire highlighted above, excluding Section 1, which focused on general information already presented in the research design and data collection account above. The direct quotations, noted below, were not linked to a specific participant so as to maintain the anonymity of each respondent.

\section{Section 2: Regulatory uncertainty}

Regulatory uncertainty was broken down into the following four aspects around agricultural legislation in the questionnaire (Table 1): (1) its general direction, (2) the operationalisation (rules, designs and measures) of future legislation, (3) the implementation process and (4) the interaction of new and existing legislation.

It appears that the interviewees were more uncertain about the general direction and implementation processes of agricultural legislation than about its operationalisation - and interaction between new and existing legislation. One of the respondents remarked that he is up to date with agricultural policies under consideration, although he is unsure about:

'... what direction government will be taking, because it is a constantly changing environment.' (Participant 5)

Four of the six parties questioned indicated that they were uncertain about the general direction, whereas half agreed that they were clear on the operationalisation of, and interaction between, new and existing agricultural legislation. All the respondents noted at least some uncertainty about the latter - five of the six specifically mentioned the uncertainty over land reform and property rights - while two interviewees described the level of uncertainty as quite a lot and a great deal of uncertainty.

A clear distinction was noticeable between the responses of the two participatory groups. The agricultural associations, although agreeing with the level of uncertainty for their members, were more confident than the agribusinesses in terms of their awareness of the regulatory landscape and associated developments, as explained in the following quotation:

'As representatives of our members, we are in a good space. Government creates consultation. The members in their operations are however in a different space.' (Participant 5)

Three participants attributed part of the regulatory uncertainty to policy complexity. Each affirmed a different driver of such complexity, namely: (1) the lack of a coherent agricultural policy, enforced by the variety of role players involved in the agricultural sector, and perceived factionalism in government, (2) a constantly changing policy environment and (3) the inability to align commercial farming interests with political ideals.

All the parties interviewed voiced their concern about the impact that the regulatory uncertainty could have on the economy of the sector. Half of them alluded to reduced investment, and even disinvestment, in the sector because of the extent of this uncertainty. One of the corporate agribusinesses averred:

'We don't know where we are heading, and it's scary.' (Participant 4)

Nevertheless, two individuals mentioned that government does create consultation opportunities for new legislation. One was fairly confident that the South African constitution presents protection in respect of the rule of law and governs the way in which the legislative process should proceed. He added that the thorough way in which legislation needs to be followed prevents sudden - and drastic - unforeseen changes in the regulatory environment.

\section{Section 3: Responses to regulatory uncertainty}

Engau and Hoffmann (2011b:70) found that firms pursue a combination of strategies (avoidance, reduction, adaptation, 
and disregard of strategies) in response to regulatory uncertainty, but to differing degrees. It appears that the study population follow suit. All of the entities represented in the interviews adopt a combination of response strategies, but in accordance with the findings of Engau and Hoffmann - to varying extents.

Engau and Hoffmann (2011a:45) initially identified 13 responses which they subsequently linked to regulatory uncertainty strategies, namely: (1) investigation, (2) influencing, (3) flexibility, (4) cooperation, (5) substitution, (6) stabilising, (7) imitation, (8) simplification, (9) internal design, (10) withdrawal; (11) integration, (12) postponement and (13) no-regret moves. The participants were asked to identify their reaction to regulatory uncertainty using these 13 responses. The strategies can be linked to the responses (in brackets) as follows: avoidance (postponement, stabilisation and withdrawal), reduction (investigation, simplification and influencing), adaptation (internal design, integration, flexibility, cooperation and imitation) and disregard (substitution and no-regret moves). There are 13 questions representing the 13 responses. However, a question relating to withdrawal (question 10 above) was omitted from the questionnaire, as it implies complete abandonment of operations (i.e. exiting from business completely), which is not realistic. The 12 responses were divided unequally between the four strategies (avoid -2 questions, reduce -3 questions, adapt -5 questions, and disregard-2 questions). To prevent this from inappropriately influencing the results, the option selected - ranging from never, considers, sometimes, often, or main activity - by the participants in response to the questions relating to avoid, reduce and disregard were all weighed as if five questions were asked. This ensured a comparable graphical representation (Figure 2).

Figure 2 shows that reduction and disregard strategies are employed to a greater extent than adaptation. Avoidance strategies are the least adopted by the participants. The results in terms of each of these strategies are elaborated on below.

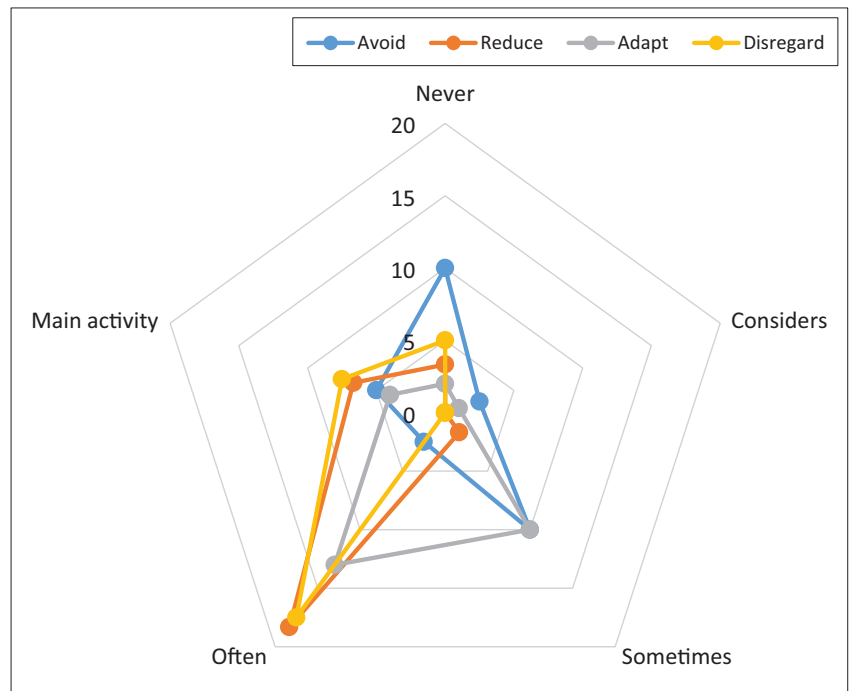

FIGURE 2: Response to regulatory uncertainty strategies.

\section{Avoidance strategies}

As mentioned above, the avoidance strategy can take the form of (1) postponement, (2) stabilisation and (3) withdrawal. Withdrawal implies leaving business in uncertain environments and focusing on more predictable circumstances (Moodley 2013:31). As mentioned above, a question on withdrawal was omitted.

Only one agricultural association indicated that postponement was one of their main activities. Two of the others would sometimes postpone strategic decisions until they had more certainty. One entity would consider postponement, and the last two indicated that they do not engage in postponement activities. One of the interviewees remarked that postponement would, in most cases, lead to missed business opportunities.

Stabilisation is created by increasing predictability through the implementation of standard procedures or the establishment of long-term contracts (Engau \& Hoffman 2011a). Two participants do not engage in stabilisation, whereas two sometimes do. One respondent considers it one of their main responses:

Unpredictability is probably the biggest enemy of business ... because business can make plans when they know what the environment is, but when you have surprise changes, that is probably the most negative impact you can have on business.

One interviewee noted that it is impossible to create predictability, with two others sharing this view.

\section{Reduction strategies}

The reduction strategy is one of the strategies that are often employed throughinvestigation, influencing and simplification. One participant sometimes chooses to influence the regulatory environment by means of engagement in the policymaking process. All the other participants either employ a reduction strategy by means of often investigating and influencing policy and policymakers (four participants in terms of investigation and three others in terms of influencing), or regard it as their main activity (two participants in terms of investigation and influencing).

It is noteworthy that the individual who indicated that their entity only sometimes takes part in the policymaking process specifically mentioned their affiliation with representative bodies engaging on their behalf. This perceived dependence on agricultural associations seems to be appropriate, as both the representatives of agricultural associations regard investigation and influencing as one of their main activities. Four interviewees also indicated that, in order to simplify decision-making, they select specific issues in their business environment to focus on. The remaining two participants do not engage in simplification at all.

\section{Adaptation strategies}

The adaptation strategy is indicated by five activities: (1) internal design, (2) integration, (3) flexibility, (4) cooperation and (5) imitation. Only one participant - representing an 
agricultural association - does not engage in rearranging the company's operations to be less exposed to regulatory uncertainty, although its members (agribusinesses) consider it a big issue. Of the remaining participants, two sometimes engage in this activity and three (half of them) often do so. One of the respondents does not engage in changing the company's organisational structure to deal better with regulatory uncertainty. On the other hand, half of the interviewees sometimes do, while one often engages, and one considers it one of their main activities. The respondent that does not engage is also the largest - in terms of turnover corporate agribusiness we studied; restructuring probably becomes more complex as firm size grows.

Five of the participants are flexible in that they enlarge their range of strategic options by preparing for more than one outcome of a policymaking process - although to differing extents: two sometimes prepare, two often do, while one regards it as one of their main activities. The remaining interviewee still prepares for more than one potential outcome of policymaking.

Cooperation is uncontestedly the most popular activity in respect of the adaptation strategy. Five participants often join forces with others whereas the remaining one considers it one of its main activities. Imitation is the second-most prevalent activity. All of the participants engage in it: half sometimes observe the activities of other companies and follow them (if appropriate), two often engage in this activity and one considers it as one of their main activities. The last is also the smallest in terms of turnover.

\section{Disregard strategies}

This response strategy is one of the most employed strategies in terms of regulatory uncertainty. It consists of no-regret moves and substitution. No-regret moves involve performing activities associated with uncertainty that have positive results regardless of how the uncertainty resolves (Engau \& Hoffmann 2011a, 2011b; Moodley 2013:31). Two respondents often engage in this activity and two others regard it as one of their main activities. The two entities that do not participate in this activity are the agricultural associations that do not operate with a profit motive. It is encouraging that all of the participants continue to make capital investments, regardless of the outcome of possible future regulation.

The disregard strategy is also driven hard by substitution by replacing uncertain decision criteria with assumptions drawn from comprehensive consideration or detailed analysis of each situation (Engau \& Hoffmann 2011a, 2011b; Moodley 2013:31). Five of the six participants often agree on the most likely regulation scenario and then focus on preparing accordingly. The sixth participant considers it as one of their main activities.

\section{Section 4: Strategy}

The purpose of this section of the questionnaire was to identify the types of CPA the participants engage in. The questions were aimed at distinguishing between reactive and proactive CPA and explored the different dimensions of these activities in terms of their approach, participation level and strategy types. It also interrogated the extent to which participants believe their CPA impacts the regulatory environment and concluded with affording the opportunity to provide additional general commentary.

\section{Proactive vs reactive corporate political activity}

Proactive CPA, also known as 'buffering', implies policy shaping by means of proactive behaviour to achieve specific political objectives, while shielding internal operations from the environment (Hillman \& Hitt 1999; Hillman et al. 2004; Mellahi et al. 2016). Buffering activities include lobbying and making campaign contributions (Hillman et al. 2004) and, more recently, also formal and informal networks, including board memberships by politicians and executives joining the political arena (Mathur \& Singh 2011). Reactive CPA - also termed 'bridging activities' - on the other hand, implies no direct participation in the public policy process (Hillman \& Hitt 1999; Hillman et al. 2004). Bridging is based on the assumption that changes to internal operations to adapt to altering external circumstances will lead to legitimisation and, ultimately, increased firm performance (Mellahi et al. 2016; Meznar \& Nigh 1995). Four of the participants found it difficult to discern a single type of CPA. They reasoned that generalisation across their entire operation is not possible, as the type of CPA applied depends on the legislation under consideration:

'... the answer lies in the dynamic nature of interaction with government, depending on the legislation.' (Participant 5)

Five of the six participants indicated that they do adapt systems and processes to ensure compliance, but only after legislative changes have been finalised - hinting towards reactive $\mathrm{CPA}$ :

'... there are so many changes that take place that it would be absolutely silly to adapt any strategy before you know exactly what the legislation is going to say.' (Participant 5)

Nevertheless, four of the five organisations that adapt systems and processes after legislative changes have been finalised, indicated that they attempt to share information with policymakers before legislation is drafted. This hints at proactive CPA. When asked bluntly to describe their CPA as either proactive or reactive, the results were equally tied between the two approaches.

This can be understood by an explanation provided by one of the participants, who distinguished between trade and transformative legislation. In respect of trade legislation, proactive CPA is employed in pursuit of competitive advantage in the market environment. Considering transformative legislation, proactive CPA is not possible due to the uncertainty associated with the legislation, and the length and complexity of the legislation process; hence, a reactive approach is followed in such cases. 
Another possible explanation for the conflicting responses can be that their ideal CPS resides with proactive CPA, proven by the strong preference for providing policymakers with information before legislation is drafted. Yet the reality and practical implications of the legislative process enforce reactive $\mathrm{CPA}$, as evidenced by the strong indication that adaptation of processes and systems is only applied after legislation has been finalised.

\section{Approach to corporate political activity}

There is a clear preference for a relational approach in the participants' approach to CPA as indicated by an interviewee who noted that:

'Our whole thing is strong relationships.' (Participant 5)

All six of the participants reported that they prefer building ongoing relationships with policymakers, as opposed to dealing with such decision-makers only when the need arises.

However, all four of the agribusinesses follow a transactional approach in as far as they wait for issues to arise before engaging and influencing policymakers, and they deal with legislative issues on an ad hoc basis. This appears to be the result of the perceived characteristics of the regulatory and legislative environment. One of the barriers to an ongoing relationship with policymakers emerged as a lack of trust in the intentions or motive of the other party. It is also argued that a lack of proper access to policymakers hampers an ongoing relationship, with one participant remarking that it is difficult to get hold of government officials, while another interviewee observed that the staff turnover is high, making it difficult to build relationships. It can be interpreted that there is a disconnect between preference - that is, relational - and ability, namely transactional, of the agribusinesses in terms of their approach to CPA.

In contrast to the above, both of the agricultural associations reported a complete alignment with a relational approach for all questions under this section, with one participant conceding that:

'... you can only really influence if you have relationships of trust.' (Participant 5)

It was clear that they do not experience the same challenges in terms of access to policymakers as the agribusiness representatives.

\section{Participation level in corporate political activity}

Participants were asked to estimate to what extent (rated in percentage) they collectively participate in CPA. Five indicated that more than $60 \%$ of the CPA they participate in is done collectively, with one of the five participants declaring $90 \%$. This correlates with results across the study - with all agribusiness participants affirming their dependence on agricultural associations when influencing the legislative process or building strong relationships with policymakers. The remaining participant indicated that $65 \%$ of their CPA participation is done on their own.

\section{Strategy types}

In this part of the questionnaire the interviewees were required to indicate to what extent they engage in the three strategy types, as well as the reason for their choice. The three strategy types are (Hillman \& Hitt 1999:834):

- Information sharing - aimed at a key policymaker and providing this person with the firm's policy preferences.

- Financial incentivisation - also directly aimed at the key policymaker and aligning incentives to the preferences of the firm through financial inducements.

- Constituent building - an indirect aim of gaining the support of voters.

Three questions were asked - one for each strategy type - to identify the appropriate strategy types followed by the participants. A participant could follow more than one strategy type. The responses to the three questions relating to the three strategy types are presented in Figure 3.

All but one participant reported that they engage in information-sharing strategies. The business that does not engage in such a strategy was the smallest company in terms of turnover and they do not engage in any other type of strategy. Participants indicated that they provide information to policymakers directly because they can only influence policy when reliable information is communicated timeously, resulting in better decision-making by government.

The financial incentivisation strategy was strongly rejected by all the participants. It is clear that this strategy is perceived as unethical as it alludes to financially incentivising policymakers to promote the policy preferences of your firm.

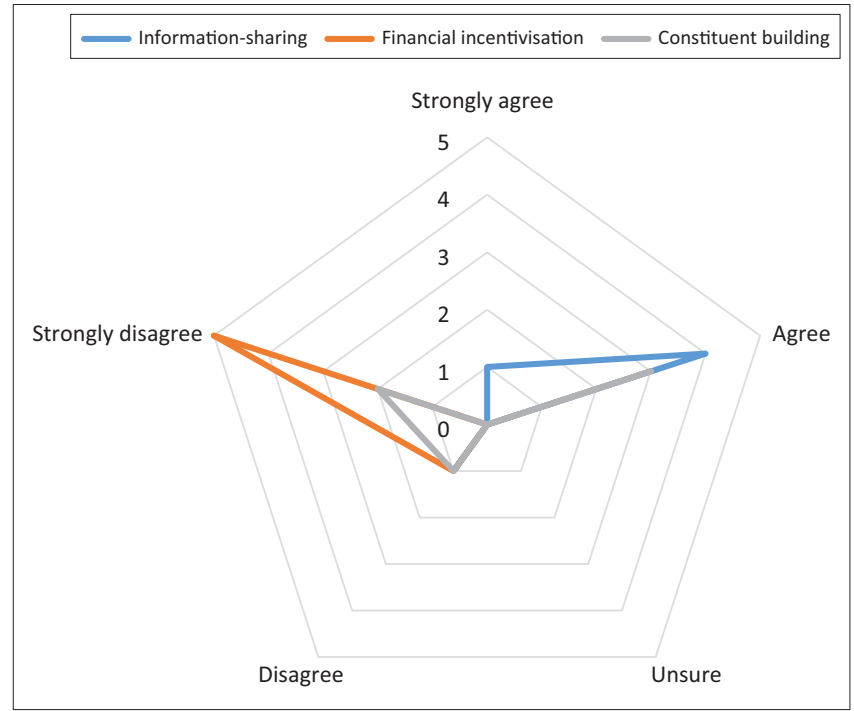

FIGURE 3: Strategy types. 
Three of our informants used the word 'bribery' and comments included:

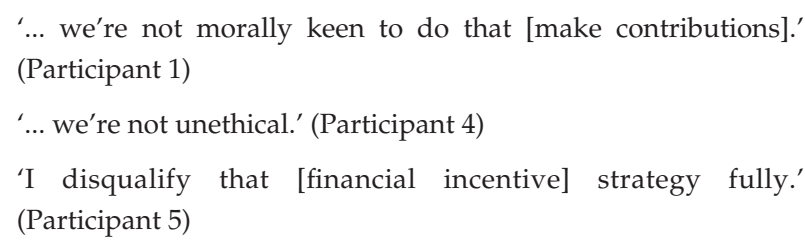

This alludes to the darker side of CPA, as discussed previously.

The two agricultural associations and one agribusiness follow the constituent building strategy with the rest declaring that they rely more on collective constituent building as done by the respective agricultural associations with which they are affiliated.

Multiple participants referred to the current political environment and barriers to access to policymakers as the reasons for their chosen strategies, with one interviewee pronouncing that they need to stay apolitical due to the sensitive nature of their customer profile. Another opined that there is a decline in regulators' comprehension of the agricultural environment. Notwithstanding that, the agricultural associations maintained that influence is dependent on integrity and maintaining a high moral ground.

\section{Perceived impact of corporate political activity}

This section of the questionnaire probed the perceived influence to shape regulation. The results produced a fairly equal spread - two participants each perceived their impact on regulation to be little, moderate and significant. The agricultural associations believed they have significant impact as they have strong relationships with policymakers and, hitherto, it has not been necessary to involve the constitutional courts. Yet they expect the relationships to be more challenging in the future, as this interview excerpt illustrates:

\footnotetext{
'The pressure is always there and it seems that the pressure is actually building, particularly in terms of access to resources, to water, to land, the compensation issue around the land ... so there's a lot of political pressure ... and it's quite a difficult climate to lobby in.... It's hard to judge by your past performances whether you will be successful in the future.' (Participant 2)
}

The two larger agribusinesses - based on turnover suggested they had only moderate impact, for differing reasons: one being a lack of direct access to policymakers, and another was that the business's board does not represent South Africa's demographics sufficiently. The second reason was also alluded to by one of the agricultural associations. They remarked that they have transformed to such an extent that they are now a better representation of the South African population, in terms of race and gender, and they argued that this was one of the reasons that their CPS is successful.
Interestingly, the two agribusinesses that believe they have little impact are the two smaller companies - based on turnover.

\section{Additional general commentary on the topic of corporate political activity}

The interviewees had varying positions and strategies in response to the regulatory environment with some participants providing positive comments by conceding the excellence of the South African constitution and legislative processes, and remarking on the majority of the South African population being reasonable. A desire for cooperation and prosperity for all surfaced in three of the interviews. Two participants explicitly stated that they are not against land reform, but that the manner in which ownership of land is transformed is of crucial importance. They opined that the integrity of the land market needs to be preserved and maintained and the changing of property rights could lead to the collapse of collateral for significant amounts of finance, which would have a devastating ripple effect on the economy as a whole. Furthermore, they posited that transformed land should remain productive because unproductive land leads to loss in economies of scale for agribusinesses.

Less positive remarks, alluding to the policy uncertainty paralysing the agricultural sector, were also made. That South Africa presents a difficult economic and political climate, and a period of uncertainty for business in general, was mentioned twice. In addition, it was averred that volatile exchange rates, the poor economic status of the country and declining investor confidence are all caused by the negative political environment and ultimately affect agribusinesses negatively. Two participants noted the adverse effect that political statements that have not been thought through have had on investor confidence. The lack of government support - for drought relief - was mentioned by two of the parties interviewed.

Another insight provided by both the smallest and largest participant was the need for better access to policymakers for lower level business and individual agribusinesses. This relates not only to influencing new legislation, but also current legislation:

'... government should maybe consult a bit more or they should be more open to interact with business on a lower level.' (Participant 3)

\section{Discussions and recommendations}

The interviews conducted confirm that the participants do engage in CPA as part of an integrated enterprise strategy to address regulatory uncertainty, and they do so in pursuit of business sustainability. There is a fundamental desire for a stable and sustainable operating environment and a call for better access to policymakers, and generally more support from government during difficult economic and uncertain times. 
A clear distinction can be drawn between the strategic approaches to CPA, followed by corporate agribusinesses and agricultural associations. The agribusinesses seem more anxious and uncertain - this can most probably be ascribed to the associations being better informed and (possibly because of) having better access to policymakers. It is therefore recommended that engagement between agricultural associations and their members should be strengthened through improved communication on topic-specific matters such as land reform and distribution, restrictive labour policies and minimum wages.

This study found that the participants experience a great deal of regulatory uncertainty, especially in terms of the general direction and implementation of future agricultural regulation and legislation. Uncertainty around land reform and property rights in South Africa is posing a substantial threat to future investment in a sector that significantly influences the country's economy. This finding partly concurs with the arguments of Kirsten (2017:14), that mass expropriation of land will lead to a lack of agricultural investments resulting ultimately in no growth in the agribusiness sector.

The findings on responses to regulatory uncertainty by participants concur with those of Engau and Hoffman (2011b:70) and Moodley (2013:77), that is, that firms follow a combination of strategies. The South African agribusinesses surveyed adopt, to varying extents, different combinations of CPA as part of their integrated enterprise strategy. They employ disregard and reduction strategies to the greatest extent and the avoidance strategy the least. The disregard strategy is adopted with the greatest alignment among participants. This finding is in contrast to the response of local firms in the health sector that followed the avoidance strategy by primarily engaging 'to a greater degree in withdrawal and stabilisation activities' (Moodley 2013:77).

A reassuring finding with regard to strategy as a whole is that a strong morality element can be traced across the results in terms of approach, participation level and strategy types. All the interviewees strongly rejected the financial incentive strategy, as they argued it is unethical and that there is a perceived connection with bribery.

Contrary to their desire to follow a relational approach, the corporate agribusinesses engage in a transactional course of action. Half of them ascribe this to a lack of direct access to policymakers. Moodley (2013:77) however found that wealthier local and foreign companies in the health sector are more relational in their approach. Mbalyoherea and Lawton (2018) also found that multinational enterprises in Uganda followed a more relational approach to CPA. The agricultural associations' results, on the other hand, are completely aligned with a relational approach. This, clearly, is one of many benefits of collectively participating in CPA, justifying the desire for such collaboration. As a result of these circumstances, it is reiterated again that agribusinesses are sufficiently involved with their respective agricultural associations, and that their views and needs are aligned.
There appears to be a disconnect between the participants' preferences and abilities in terms of the type of CPA they apply. Contradictory opinions expressed by the interviewees indicate that there is a definite desire to engage in proactive CPA, yet - depending on the type of legislation - the lengthy and complex legislative process and uncertain regulatory environment sometimes push participants towards reactive CPA. Moodley (2013:76) found that foreign companies are more proactive in their CPA than local firms in the South African health sector.

During the opportunity given to raise general comments, the participants remarked that, although they are not against land reform, the process should be steered responsibly to ensure that the productivity of land is maintained and its value used as collateral in finance - is upheld. This view is shared and expanded by Boshoff et al. (2018:10) that, other than the financial aspects of land reform, there are other concerns related to policy design that require attention. These include not only legislative interventions recognising a variety of rights in communal areas, but also the direction of land reform programmes towards inclusive agrarian transformation.

A limitation of this study is that the sample size of six participants is small. We tried to overcome this by recruiting the representation of agribusinesses representing a significant annual turnover of R24.6 billion. Another limitation is that the results are focused on only two kinds of stakeholders in the agricultural sector - corporate agribusinesses and agricultural associations. This limitation creates an opportunity to extend this study to include policymakers and officials from the South African Department of Rural Development and Land Reform and the Department of Agriculture, Forestry and Fisheries.

\section{Concluding remarks}

It was revealed that both corporate agribusinesses and agricultural associations do engage in CPA as part of their enterprise strategy, although to differing extents. Furthermore, the qualitative data represent the viewpoints of two kinds of key stakeholders in this employment-intensive sector corporate agribusiness and agricultural associations especially during this time of regulatory uncertainty. This research provides insight into what responses agribusinesses and agricultural associations employ in response to regulatory uncertainty, and furthermore what strategies they follow to engage government.

This research will be useful to policymakers, corporate board members, government officials, and fellow researchers in their aim to enhance collaboration between the state and the private sector, especially during times of regulatory uncertainty. This article is the first step towards reporting on CPA in the agricultural sector in South Africa and it emphasises the necessity and need for increasing interaction between government and representatives of the agricultural industry. Fellow researchers are encouraged to expand and continue conducting research in this 'virgin region'. 


\section{Acknowledgements}

The authors gratefully acknowledge the input provided by the reviewers in improving the quality of the article.

\section{Competing interests}

The authors declare that they have no financial or personal relationships that may have inappropriately influenced them in writing this article.

\section{Authors' contributions}

L.B. was the principal researcher that conducted the fieldwork and data collection and analysis. S.L.M. acted as supervisor and co-wrote and finalised the article.

\section{Funding information}

The authors gratefully acknowledge the National Research Foundation for providing financial support.

\section{Data availability statement}

Data sharing is not applicable to this article as no new data were created or analysed in this study.

\section{Disclaimer}

The views expressed in this article are the authors' own and do not necessarily reflect the opinions of the institution or funder.

\section{References}

African National Congress, 2016, The freedom charter, viewed 02 December 2016, from https://www.anc1912.org.za/freedom-charter.

Aggarwal, R.K., Meschke, F. \& Wang, T.Y., 2012, 'Corporate political donations: Investment or agency?', Business \& Politics 14(1), 1-38. https://doi.org/10.1515/ 1469-3569.1391

Baron, D.P., 1995, 'Integrated strategy: Market and nonmarket components', California Management Review 37(2), 47-65. https://doi.org/10.2307/41165788

Baysinger, B.D., 1984, 'Domain maintenance as an objective of business political activity: An expanded typology', Academy of Management Review 9(2), 248-258. https://doi.org/10.5465/amr.1984.4277642

Bliss, M.A. \& Gul, F.A., 2012, 'Political connection and cost of debt: Some Malaysian evidence', Journal of Banking \& Finance 36(5), 1520-1527. https://doi.org/10.1016/ j.jbankfin.2011.12.011

Booysen, D.V., 2016, 'Plase: Geen tekort aan "gewillige verkopers"', Netwerk24, viewed 02 June 2016, from http://www.netwerk24.com/Sake/Eiendomme/plasegeen-tekort-aan-gewillige-verkopers-20160602.

Boshoff, T., Sihlobo, W. \& Ntombela, S., 2018, 'Redistribution of agricultural land: Expropriation without compensation debate', viewed 02 May 2019, from https:// webcache.googleusercontent com/search?q=cache:s7hffXMh9hkJ:https://agbiz. co.za/uploads/AgbizNews18/EXPROPRIATION_WITHOUT_COMPENSATION DEBATE. pdf $\& c d=2 \& h l=e n \& c t=c \mid n k \& g l=z a$.

Boubakri, N., Cosset, J.C. \& Saffar, W., 2012, 'The impact of political connections on firms' operating performance and financing decisions', Journal of Financial Research 35(3), 397-423. https://doi.org/10.1111/j.1475-6803.2012.01322.x

Caspari, C. \& Caspari, M., 2016, 'Strategic planning moving ideas to practice', Camping Magazine 89(2), 56.

Chamberlain, W.O. \& Anseeuw, W., 2018, 'Inclusive businesses and land reform: Corporatization or transformation?', Land 7(1), 1-17. https://doi.org/10.3390/ land7010018

Crilly, D., 2013, 'Recasting enterprise strategy: Towards stakeholder research that matters to general managers', Journal of Management Studies 50(8), 1427-1447. https://doi.org/10.1111/joms.12053

Curran, L. \& Eckhardt, J., 2018, 'Influencing trade policy in a multi-level system Understanding corporate political activity in the context of global value chains and regime complexity', Business \& Politics 20(1), 132-164. https://doi.org/10.1017/ bap. 2017.26
DiCicco-Bloom, B. \& Crabtree, B.F., 2006, 'The qualitative research interview', Medical Education 40(4), 314-321. https://doi.org/10.1111/j.1365-2929.2006.02418.x

Doh, J.P., Lawton, T.C. \& Rajwani, T., 2012, 'Advancing nonmarket strategy research: Institutional perspectives in a changing world', The Academy of Management Perspectives 26(3), 22-39. https://doi.org/10.5465/amp.2012.0041

Economic Freedom Fighters, 2019, Economic freedom fighters central command press statement, viewed 13 May 2019, from http://www.effonline.org/News.

Electoral Commission, 2019, 2019 National and provincial election results (downloadable), viewed 13 May 2019, from https://www.elections.org.za/ ieconline/Reports/National-and-Provincial-reports.

Engau, C. \& Hoffmann, V.H., 2011a, 'Corporate response strategies to regulatory uncertainty: Evidence from uncertainty about post-Kyoto regulation', Policy Sciences 44(1), 53-80. https://doi.org/10.1007/s11077-010-9116-0

Engau, C. \& Hoffmann, V.H., 2011b, 'Strategizing in an unpredictable climate: Exploring corporate strategies to cope with regulatory uncertainty', Long Range Planning 44(1), 42-63. https://doi.org/10.1016/j.lrp.2010.11.003

Etikan, I., Musa, S.A. \& Alkassim, R.S., 2016, 'Comparison of convenience sampling and purposive sampling', American Journal of Theoretical and Applied Statistics 5(1), 1-4. https://doi.org/10.11648/j.ajtas.20160501.11

Fanadzo, M. \& Ncube, B., 2018, 'Challenges and opportunities for revitalising smallholder irrigation schemes in South Africa', Water SA 44(3), 436-447. https:// doi.org/10.4314/wsa.v44i3.11

February, J., 2017, 'The time has come for years of inaction around funding of political parties to turn to action', Daily Maverick, viewed 22 June 2016, from https:// www.dailymaverick.co.za/opinionista/2017-05-19-the-time-has-come-for-yearsof-inaction-around-funding-of-political-parties-to-turn-to-action/.

Godinez, J. \& Garita, M., 2016, 'The dimensions of corruption and its impact on FDI decision making: The case of Guatemala', Business and Politics 18(2), 123-141. https://doi.org/10.1515/bap-2013-0033

Greenberg, S., 2010, Status report on land and agricultural policy in South Africa, Institute for Poverty, Land and Agrarian Studies research report no. 40, PLAAS, Cape Town.

Griffin, J.J. \& Dunn, P., 2004, 'Corporate public affairs: Commitment, resources, and structure', Business \& Society 43(2), 196-220. https://doi.org/10.1177/000765030 4266277

Hadani, M. \& Schuler, D.A., 2013 'In search of El Dorado: The elusive financial returns on corporate political investments', Strategic Management Journal 34(2), 165-181. https://doi.org/10.1002/smj.2006

Hall, R., 2004, 'A political economy of land reform in South Africa', Review of African PoliticalEconomy31(100),213-227.https://doi.org/10.1080/0305624042000262257

Hall, R. \& Cousins, B., 2018, 'Exporting contradictions: The expansion of South African agrarian capital within Africa', Globalizations 15(1), 12-31. https://doi.org/10.1080/ 14747731.2017.1408335

Hendriks, S., 2013, 'South Africa's National Development Plan and New Growth Path: Reflections on policy contradictions and implications for food security', Agrekon 52(3), 1-17. https://doi.org/10.1080/03031853.2013.821741

Hillman, A.J. \& Hitt, M.A., 1999, 'Corporate political strategy formulation: A model of approach, participation, and strategy decisions', Academy of Management Review 24(4), 825-842. https://doi.org/10.5465/amr.1999.2553256

Hillman, A.J., Keim, G.D. \& Schuler, D., 2004, 'Corporate political activity: A review and research agenda', Journal of Management 30(6), 837-857. https://doi. org/10.1016/j.jm.2004.06.003

Hond, F., Rehbein, K.A., Bakker, F.G. \& Lankveld, H.K.V., 2014, 'Playing on two chessboards: Reputation effects between corporate social responsibility (CSR) and corporate political activity (CPA)', Journal of Management Studies 51(5), 790-813. https://doi.org/10.1111/joms.12063

Khapayi, M. \& Celliers, P.R., 2016, 'Factors limiting and preventing emerging farmers to progress to commercial agricultural farming in the King William's town area of the Eastern Cape province, South Africa', South African Journal of Agricultural Extension 44(1), 25-41. https://doi.org/10.17159/2413-3221/2016/v44n1a374

Keim, G.D., 1981, 'Foundations of a political strategy for business', Californic Management Review 23(3), 41-48. https://doi.org/10.2307/41172600

Kingsley, A.F., Bergh, R.G.V. \& Bonardi, J.P., 2012, 'Political markets and regulatory uncertainty: Insights and implications for integrated strategy', The Academy of Management Perspectives 26(3), 52-67. https://doi.org/10.5465/amp.2012.0042

Kirsten, J.F., 2017, 'Reflections on 25 years of engagement with the land question in South Africa', viewed 02 May 2019, from http://www.sun.ac.za/english/ Inaugurallectures/Inaugural\%20lectures/InauguralLectureProfJFKirsten.pdf.

Lawton, T., McGuire, S. \& Rajwani, T., 2013, 'Corporate political activity: A literature review and research agenda', International Journal of Management Reviews 15(1), 86-105. https://doi.org/10.1111/j.1468-2370.2012.00337.x

Liedong, T.A., 2013, 'Corporate political activity and firm performance - A systematic review', M thesis, School of Management, Cranfield University.

Liedong, T.A., Ghobadian, A., Rajwani, T. \& O'Regan, N., 2015, 'Toward a view of complementarity: Trust and policy influence effects of corporate social responsibility and corporate political activity', Group \& Organization Management 40(3), 405-427. https://doi.org/10.1177/1059601114560064

Lu, Y., 2011, 'Political connections and trade expansion', Economics of Transition 19(2), 231-254. https://doi.org/10.1111/j.1468-0351.2010.00402.x

Mathur, I. \& Singh, M., 2011, 'Corporate political strategies', Accounting \& Finance 51(1), 252-277. https://doi.org/10.1111/j.1467-629X.2010.00386.x 
Mbalyoherea, C. \& Lawton, T.C., 2018, 'Engaging stakeholders through corporate political activity: Insights from MNE nonmarket strategy in an emerging African
market', Journal of International Management 24(2018), 369-385. https://doi. market', Journal of International Mar

Mellahi, K., Frynas, J.G., Sun, P. \& Siegel, D., 2016, 'A review of the nonmarket strategy literature: Toward a multi-theoretical integration', Journal of Management 42(1), 143-173. https://doi.org/10.1177/0149206315617241

Meznar, M.B. \& Nigh, D., 1995, 'Buffer or bridge? Environmental and organizational determinants of public affairs activities in American firms', Academy of Management Journal 38(4), 975-996. https://doi.org/10.2307/256617

Middelberg, S.L., 2011, 'The accountancy implications of commodity derivatives in the agricultural sector', PhD thesis, School of Accounting Sciences, North-West University.

Middelberg, S.L., 2013, 'Sustainable agriculture: A review of challenges facing the South African agricultural sector', Journal of Human Ecology 42(2), 163-169. https://doi.org/10.1080/09709274.2013.11906590

Moodley, T., 2013, 'Corporate political activity: A comparison of local and foreign company strategies', MBA dissertation, GIBS, University of Pretoria.

Ncube, B., 2018, 'Constraints to smallholder agricultural production in the Western Cape, South Africa', Physics and Chemistry of the Earth 106, 89-96. https://doi. org/10.1016/j.pce.2018.05.012

Neuman, W.L., 2014, Social research methods: Qualitative and quantitative approaches, 7th edn., Pearson Education Limited, Edinburgh.

Ortmann, G.F., 2005, 'Promoting the competitiveness of South African agriculture in a dynamic economic and political environment', Agrekon 44(3), 286-320. https:// doi.org/10.1080/03031853.2005.9523714

Ramaphosa, C., 2017, 'Closing address by ANC president', News24, viewed 29 January 2018, from https://www.news24.com/Columnists/GuestColumn/ramaphosas-firstaddress-as-anc-president-read-the-full-speech-20171221.
Schendel, D. \& Hofer, C.W., 1979, Strategic management: A new view of business policy and planning, 2 nd edn., Little, Brown and Company, Detroit, MI.

Shultz, C.J. \& Edwards, M.R., 2005, 'Reframing agribusiness: Moving from farm to market centric', Journal of Agribusiness 23(1), 57-73.

Smith, C., 2016, 'Policy uncertainty frustrating SA's agricultural development', Fin24, viewed 02 May 2019, from https://www.fin24.com/Economy/policy-uncertaintyfrustrating-sas-agricultural-development-20161219.

South African Government, 2016, Agriculture, viewed 01 August 2016, from http:// www.gov.za/node/72.

Sun, P., Mellahi, K. \& Wright, M., 2012, 'The contingent value of corporate political ties', The Academy of Management Perspectives 26(3), 68-82. https://doi.org/ 10.5465/amp.2011.0164

Swarts, M.B. \& Aliber, M., 2013, 'The "youth and agriculture" problem: Implications for rangeland development', African Journal of Range \& Forage Science 30(1-2), 23-27. https://doi.org/10.2989/10220119.2013.778902

Tharenou, P., Saks, A.M. \& Moore, C., 2007, 'A review and critique of research on training and organizational-level outcomes', Human Resource Management Review 17(3), 251-273. https://doi.org/10.1016/j.hrmr.2007.07.004

Tian, Z. \& Deng, X., 2007, 'The determinants of corporate political strategy in Chinese transition', Journal of Public Affairs 7(4), 341-356. https://doi.org/10.1002/pa.273

Transparency International, 2018, South Africa, viewed 02 May 2019, from http:// www.transparency.org/country/\#ZAF.

Vorster, T., De Villiers, J., McBain, H. \& Nchocho, T., 2016, Nation in conversation: Policy matters, viewed 22 June 2016, from http://www.nationinconversation. co.za/en-ZA/News/Article/View/nation-in-conversation-policy-matters.

Wu, W., Wu, C., Zhou, C. \& Wu, J., 2012, 'Political connections, tax benefits and firm performance: Evidence from China', Journal of Accounting and Public policy 31(3) 277-300. https://doi.org/10.1016/j.jaccpubpol.2011.10.005 